\title{
Glucose-induced Protein Kinase C Activity Regulates Arachidonic Acid Release and Eicosanoid Production by Cultured Glomerular Mesangial Cells
}

\author{
Bryan Williams and Robert W. Schrier \\ Department of Medicine, University of Colorado Health Sciences Center, Denver, Colorado 80262
}

\begin{abstract}
Changes in glomerular eicosanoid production have been implicated in the development of diabetes-induced glomerular hyperfiltration and glomerular mesangial cells (GMC) are major eicosanoid-producing cells within the glomerulus. However, the mechanism for the effect of diabetes mellitus on glomerular mesangial eicosanoid production is unknown. The present study therefore examined whether elevated glucose concentrations activate protein kinase C (PKC) in GMC and whether this PKC activation mediates an effect of elevated glucose concentrations to increase the release of arachidonic acid and eicosanoid production by GMC. The percentage of $\left[{ }^{3} \mathrm{H}\right]$ arachidonic acid release per $30 \mathrm{~min}$ by preloaded GMC monolayers was significantly increased after 3-h exposure to high glucose (20 $\mathrm{mM}$ ) medium ( $177 \%$ vs control medium) and this increase was sustained after 24-h exposure to high glucose concentrations. 3-h and 24-h exposure to high glucose medium also increased $\mathrm{PGE}_{2}, 6$-keto-PGF $1 \alpha$, and thromboxane $\left(\mathrm{TXB}_{2}\right)$ production by GMC. High glucose medium ( $20 \mathrm{mM}$ ) increased PKC activity in GMC at 3 and $24 \mathrm{~h}$ ( $168 \%$ vs control). In contrast, osmotic control media containing either L-glucose or mannitol did not increase arachidonic acid release, eicosanoid production, or $P K C$ activity in GMC. Inhibiting glucose-induced PKC activation with either $\mathrm{H}-7$ ( $50 \mu \mathrm{M})$ or staurosporine ( $1 \mu \mathrm{M})$ prevented glucose-induced increases in arachidonic acid release and eicosanoid production by GMC. These data demonstrate that elevated extracellular glucose concentrations directly increase the release of endogenous arachidonic acid and eicosanoids by GMC via mechanisms dependent on glucose-induced PKC activation. (J. Clin. Invest. 1993. 92:2889-2896.) Key words: glucose $\bullet$ protein kinase $C \bullet$ mesangial cell $\bullet$ arachidonic acid • eicosanoids
\end{abstract}

\section{Introduction}

Diabetes mellitus in experimental animals and humans is associated with qualitative and quantitative changes in PG and TX production by many tissues (1-13). With regard to the kidney, previous studies demonstrate increased production of $\mathrm{PGE}_{2}$, 6-keto-PGF $\mathrm{PG}_{1 \alpha}$, and $\mathrm{TXB}_{2}$ by glomeruli isolated from rats with early streptozotocin-induced diabetes mellitus $(8,9,11-13)$.

Address correspondence to Robert W. Schrier, M.D., Professor and Chairman, Department of Medicine, Box C-281, University of Colorado Health Sciences Center, 4200 East Ninth Avenue, Denver, CO 80262.

Received for publication 11 December 1992 and in revised form 9 July 1993.

J. Clin. Invest.

(C) The American Society for Clinical Investigation, Inc. $0021-9738 / 93 / 12 / 2889 / 08 \quad \$ 2.00$

Volume 92, December 1993, 2889-2896
These changes have in turn been implicated in the pathogenesis of glomerular hemodynamic abnormalities that may play a role in the development of diabetic glomerulopathy $(8,9,12,14)$.

The mechanisms responsible for diabetes-induced changes in glomerular eicosanoid production are unclear but may depend on increased release of arachidonic acid $(8,9)$, perhaps via diabetes-induced increases in glomerular phospholipase $\mathrm{A}_{2}$ activity (15). Thus far, however, the factors and mechanisms responsible for these diabetes-induced increases in $\mathrm{PLA}_{2}$ activity and arachidonic acid release are unknown. Hyperglycemia is the hallmark of diabetes mellitus, thus glucose has to be considered as a potential mediator of increased glomerular eicosanoid production. In this regard, a previous study has shown that when exposed to elevated extracellular glucose concentrations, cultured glomerular mesangial cells (GMC) ${ }^{1}$ produce increased quantities of prostaglandin, predominantly $\mathrm{PGE}_{2}(9)$.

The GMC is a major prostanoid-producing cell within the glomerulus and the rate of endogenous arachidonic acid release is usually rate limiting for GMC eicosanoid synthesis (16). Recent evidence suggests that activation of the calcium/phospholipid-dependent protein kinase $C$ system ( $P K C$ ) plays a key role in regulating arachidonic acid release by many cell types, including GMC (17-26). Moreover, PKC activation may also increase $\mathrm{PGE}_{2}$ production by $\operatorname{GMC}(17,26,27)$. These observations are intriguing because high glucose concentrations have been shown to increase PKC activity in many tissues in vivo and in many cell types in vitro (28-33).

Taken together, the aforementioned observations suggest that glucose may directly influence GMC arachidonic acid release and eicosanoid production via mechanisms dependent on glucose-induced PKC activation. Examining this hypothesis in vivo would be impossible because diabetes mellitus is associated with a myriad of metabolic and hormonal changes that could influence PKC activity and eicosanoid production by GMC. Thus, the present study uses cultured GMC in vitro to test the hypothesis that elevated extracellular glucose concentrations directly increase arachidonic acid release and prostaglandin production by GMC via mechanisms dependent on glucose-induced PKC activation.

\section{Methods}

Glomerular mesangial cell culture

GMC were cultured from glomeruli isolated from 200-300-g nondiabetic Sprague Dawley rats as previously described in detail $(34,35)$. The GMC were grown as monolayers on $35-\mathrm{mm}$ culture dishes in RPMI 1640 buffered with $10 \mathrm{mM}$ Hepes at pH 7.4 and were supplemented with $20 \%$ FCS, $5 \mu \mathrm{g}$ human transferrin, $200 \mathrm{mg} / \mathrm{liter}$

1. Abbreviations used in this paper: DAG, diacylglycerol; GMC, glomerular mesangial cell; PKC, protein kinase C; $\mathrm{PLA}_{2}$, phospholipase $\mathrm{A}_{2} ;$ PSS, physiologic salt solution. 
$\mathrm{HaHCO}_{3}, 100 \mathrm{U} / \mathrm{ml}$ penicillin, and $100 \mu \mathrm{g} / \mathrm{ml}$ streptomycin. Once confluent, the cells were passaged after incubation with $0.5 \mathrm{ml} 0.25 \%$ trypsin and $0.01 \%$ EDTA for $10 \mathrm{~min}$ at $37^{\circ} \mathrm{C}$. Studies were performed on GMC monolayers at 4th through 10th passage.

\section{Experimental design}

When confluent, GMC monolayers were exposed to one of four test culture media described below.

Control medium. This comprised standard GMC culture medium as described above (D-glucose concentration $5 \mathrm{mM} /$ liter).

High glucose medium. This medium was identical to control medium but with a D-glucose concentration of $20 \mathrm{mM} /$ liter.

Mannitol medium. This was identical to control medium but supplemented with mannitol (D-glucose $5 \mathrm{mM} /$ liter plus mannitol 15 $\mathrm{mM} /$ liter), a cell impermeable hexose.

L-Glucose medium. This was identical to control medium but supplemented with L-glucose (D-glucose $5 \mathrm{mM} /$ liter plus L-glucose 15 $\mathrm{mM} /$ liter), a cell-permeable but poorly metabolized glucose isomer. The mannitol and L-glucose contained an osmotic load equivalent to the high glucose medium and thus served as osmotic controls. Because L-glucose is poorly metabolized, this medium also served as a metabolic control for the high D-glucose medium.

After exposure to the test media for either 3 or $24 \mathrm{~h}$ in an incubator at $37^{\circ} \mathrm{C}$, the medium was removed by aspiration and the GMC monolayers were gently washed with $2 \mathrm{ml}$ of a physiologic salt solution (PSS) $\left(37^{\circ} \mathrm{C}, \mathrm{pH} \mathrm{7.4)}\right.$. The monolayers were then incubated for $30 \mathrm{~min}$ with $1 \mathrm{ml}$ fresh PSS supplemented with 0.1\% BSA and either D-glucose, mannitol, or L-glucose as appropriate to mimic the composition of the test media to which the cells were previously exposed. At the end of this incubation, a 900- $\mu$ l aliquot of the supernatant was removed and immediately frozen and stored at $-20^{\circ} \mathrm{C}$ until assayed to determine the quantity of eicosanoids released by the GMC monolayers in response to the different media conditions. The GMC monolayers were then solubilized with $0.1 \%$ sodium dodecyl sulfate and $0.1 \mathrm{~N} \mathrm{NaOH}$ and a $50-\mu l$ aliquot of the cell solution taken for assay of protein content per dish using the method of Lowry (36).

\section{Assay of prostaglandins and thromboxane}

The quantity of $\mathrm{PGE}_{2}$, 6-keto $\mathrm{PGF}_{1 \alpha}$ (the stable metabolite of $\mathrm{PGI}_{2}$ or prostacyclin), and $\mathrm{TXB}_{2}$ (the stable metabolite of $\mathrm{TXA}_{2}$ ) in the GMC supernatants was determined using an ELISA technique as described by Pradelles et al. (37). Briefly, 50- $\mu$ l aliquots of the GMC supernatant were assayed without prior purification. $50 \mu \mathrm{l}$ of each sample or buffer ( $0.1 \mathrm{M}$ potassium phosphate, $0.01 \% \mathrm{NaN}_{3}, 0.4 \mathrm{M} \mathrm{NaCl}, 1 \mathrm{mM}$ EDTA, and $0.1 \%$ BSA, pH 7.4) was added to each well of a 96-well microliter plate which was previously coated with goat anti-rabbit IgG antibody $(2 \mu \mathrm{g} /$ well $)$. Enzyme tracer $(50 \mu \mathrm{l})$ consisting of either $\mathrm{PGE}_{2}, 6$-keto$\mathrm{PGF}_{1 \alpha}$, or $\mathrm{TXB}_{2}$ covalently linked to purified acetylcholinesterase from electric eel was added. Finally, $50 \mu \mathrm{l}$ of the appropriate eicosanoid-specific antiserum was added and the plates were incubated for $16-24 \mathrm{~h}$ at $4^{\circ} \mathrm{C}$ before washing with $10^{-2} \mathrm{M}$ phosphate buffer, $\mathrm{pH} 7.4$, containing $0.05 \%$ Tween 20 , using an automatic plate washer (Flow Labs Inc., McLean, VA). The plates were then automatically filled with $200 \mu \mathrm{l} /$ well of the following medium: $2 \mu \mathrm{g} / \mathrm{ml}$ acetylthiocholine iodide and $2.15 \mu \mathrm{g} / \mathrm{ml}$ of 5-5'-dithiobis (2-nitrobenzoic acid) in $10^{-2}$ $M$ phosphate buffer. The production of a yellow colored product was measured at $414 \mathrm{~nm}$ using an automatic plate reader (Titertek Multiscan MC; Flow Labs). Each sample was assayed in duplicate. Nonspecific binding was determined using an incubation mixture in which the specific antibody was replaced by $50 \mu \mathrm{l}$ of assay buffer. A standard curve was constructed by plotting B/Bo\% (absorbance measured on the bound fraction in the presence of eicosanoid competitor divided by the absorbance in the absence of competitors) vs picograms eicosanoid per well. Fitting of the standard curve and calculation of the quantity of eicosanoid in the sample were performed using a nonlinear curve fitting program (38). Cross-reactivity between each specific antibody and eicosanoids, exogenous arachidonic acid and/or their metabolites was in each case $<1 \%$.

\section{Assay of $\left[{ }^{3} \mathrm{H}\right]$ arachidonic acid release by GMC}

To determine the effects of a 3-h exposure to the various test media on endogenous arachidonic acid release by GMC, the GMC arachidonic acid pool was radiolabeled by exposing GMC monolayers for $24 \mathrm{~h}$ to control medium supplemented with $0.5 \mu \mathrm{Ci} / \mathrm{ml}\left[{ }^{3} \mathrm{H}\right]$ arachidonic acid $\left(1,5,6,8,9,11,12,14,15-\left[{ }^{3} \mathrm{H}\right]\right.$ arachidonic acid, $\left.214 \mathrm{Ci} / \mathrm{mmol}\right)$. The radioactive medium was then aspirated and the GMC monolayers were washed rapidly with $10 \times 1 \mathrm{ml}$ PSS supplemented with $0.1 \%$ BSA. The $\left[{ }^{3} \mathrm{H}\right]$ arachidonic acid-labeled GMC monolayers were incubated with the various test media for $3 \mathrm{~h}$ at $37^{\circ} \mathrm{C}$. Thereafter, the test medium was aspirated and replaced with $1 \mathrm{ml}$ of fresh test medium and incubated for a further $30 \mathrm{~min}$. A $900-\mu \mathrm{l}$ aliquot of the medium overlying the cells was removed and retained for scintillation counting of the quantity of $\left[{ }^{3} \mathrm{H}\right]$ arachidonic acid released by GMC into the test medium per 30 min (Tri-carb 460C; Packard, Downer's Grove, IL). The GMC monolayer was washed rapidly ( $10 \times 1 \mathrm{ml}$ PSS plus $0.1 \%$ BSA $)$, solubilized, and the protein content was determined as described above. A sample of the solubilized GMC monolayer was retained for scintillation counting of the quantity of $\left[{ }^{3} \mathrm{H}\right]$ arachidonic acid retained by the GMC. The amount of radioactive arachidonic acid released per 30 min was expressed as a percentage of the total radioactivity available for release (i.e., released plus GMC radioactivity).

To study the effects of 24-h incubation with the test media on the release of arachidonic acid by GMC, a similar protocol was used but the test media was supplemented with $0.5 \mu \mathrm{Ci}\left[{ }^{3} \mathrm{H}\right.$ ] arachidonic acid during the 24-h incubation period with the test media to achieve GMC loading. The various test media did not influence GMC loading with $\left[{ }^{3} \mathrm{H}\right.$ ] arachidonic acid over the 24-h exposure. After incubation, the GMC monolayers were washed and incubated with fresh test medium for $30 \mathrm{~min}$ to determine the impact of prolonged exposure to the test media on the release of $\left[{ }^{3} \mathrm{H}\right]$ arachidonic acid from GMC as described above.

\section{Effect of test media on $\left[{ }^{3} \mathrm{H}\right]$ arachidonate reincorporation by $G M C$}

The quantity of $\left[{ }^{3} \mathrm{H}\right]$ arachidonate measured in the medium overlying the GMC monolayer is determined not only by its rate of release but also by its rate of reincorporation by GMC. To determine whether the test media influenced the rate of $\left[{ }^{3} \mathrm{H}\right]$ arachidonate incorporation, GMC monolayers were preexposed to the various test media for $24 \mathrm{~h}$. Thereafter, the medium was aspirated and replaced with a similar test medium supplemented with $0.5 \mu \mathrm{Ci}\left[{ }^{3} \mathrm{H}\right.$ ] arachidonate for $30 \mathrm{~min}$. The radioactive medium was then removed and retained for scintillation counting. The GMC monolayers were washed rapidly $(10 \times 1 \mathrm{ml}$ PSS plus $0.1 \%$ BSA), solubilized, and an aliquot of the cell solution was taken for counting of the radioactivity incorporated by GMC. The quantity of $\left[{ }^{3} \mathrm{H}\right]$ arachidonic acid incorporated by GMC per $30 \mathrm{~min}$ was expressed as a percentage of total radioactivity available for incorporation (i.e., radioactive supernatant counts plus GMC associated counts).

\section{Measurement of $P K C$ activity in $G M C$}

PKC activity in GMC monolayers was measured using a modification of the method recently described by Heasley and Johnson $(39,40)$. This method has been validated previously in our laboratory and used to characterize in situ PKC activation in cultured vascular smooth muscle cells (33). GMC were seeded onto flat-bottomed 96-well microtiter plates at a density of $\sim 20,000$ / well and maintained in regular growth medium for $3 \mathrm{~d}$ until confluent. GMC monolayers were then incubated with the test media for 3 or $24 \mathrm{~h}$. After incubation, the test medium was aspirated and replaced with $40 \mu \mathrm{l}$ of a buffered salt solution containing $137 \mathrm{mM} \mathrm{NaCl}, 5.4 \mathrm{mM} \mathrm{KCl}, 10 \mathrm{mM} \mathrm{MgCl}, 0.3 \mathrm{mM}$ sodium phosphate, $0.4 \mathrm{mM}$ potassium phosphate, $25 \mathrm{mM} \beta$-glycerophosphate, $5.5 \mathrm{mM}$ D-glucose, $5 \mathrm{mM}$ EGTA, $1 \mathrm{mM} \mathrm{CaCl} 2(\sim 100 \mathrm{nM}$ free $\left.\mathrm{Ca}^{2+}\right), 100 \mu \mathrm{M}\left[\tau-{ }_{-32} \mathrm{P}\right]$ ATP $(\sim 5,000 \mathrm{cpm} / \mathrm{pmol}), 50 \mu \mathrm{g} / \mathrm{ml}$ digitonin, and $20 \mathrm{mM}$ Hepes ( $\left.\mathrm{pH} 7.2,37^{\circ} \mathrm{C}\right)$. In addition, $100 \mu \mathrm{M}$ of a PKC-specific peptide substrate (VRKRTLRRL) was added to the 
buffer. This short synthetic peptide is based on the sequence surrounding a major PKC-dependent phosphorylation site within the epidermal growth factor receptor (41). This peptide substrate is not phosphorylated by cyclic nucleotide-dependent or $\mathrm{Ca}^{2+} /$ calmodulin-dependent protein kinases or $\mathrm{S} 6$ kinase and has been extensively characterized to be highly specific for $\operatorname{PKC}(39,40)$. By permeabilizing the GMC with the digitonin contained in the buffer, the VRKRTLRRL peptide enters the GMC along with $\left[\tau-{ }^{32} \mathrm{P}\right] \mathrm{ATP}$ to allow a highly selective and rapid analysis of in situ PKC activity. Similar to our findings with vascular smooth muscle cells, the concentration of digitonin used $(50 \mu \mathrm{g} / \mathrm{ml})$ did not modify GMC morphology or promote cell detachment. In addition, PKC activity was retained by the monolayer after permeabilization (PKC activity in supernatant was $7.3 \%$ of total measured PKC activity). This latter finding is consistent with the concept that the PKC activity being assayed was tightly associated with the cell membrane as has been proposed for the active form of the kinase (42). The kinase reaction was linear for up to $20 \mathrm{~min}$ and was thus allowed to proceed for $10 \mathrm{~min}$ at $30^{\circ} \mathrm{C}$ before termination of the assay by the addition of 50 $\mu \mathrm{l}$ ice cold $25 \%(\mathrm{wt} / \mathrm{vol}$ ) trichloracetic acid (final TCA concentration $5 \%)$. Aliquots $(45 \mu \mathrm{l})$ of the acidified reaction mixture were then spotted onto 2-cm phosphocellulose paper circles (P81; Whatman Inc., Clifton, NJ) and washed batchwise; three washes with $75 \mathrm{mM}$ phosphoric acid and one wash with $75 \mathrm{mM}$ sodium phosphate (pH 7.5) (500 $\mathrm{ml} / 2$-min wash). Due to the basicity of the VRKRTLRRL substrate, it was retained by the phosphocellulose filter at neutral $\mathrm{pH}$, while contaminating $\left[\tau-{ }^{32} \mathrm{P}\right]$ ATP was removed. The PKC-dependent phosphorylation of the peptide substrate bound to the filter was quantified by scintillation counting. Background phosphorylation was assessed in two ways: (a) Immediately before the addition of the reaction buffer, $40 \mu \mathrm{l}$ of ice cold TCA was added to precipitate cellular protein and eliminate kinase activity. The TCA was aspirated, the reaction buffer was added, and the assay was performed as described above to determine the kinase-independent phosphorylation of the VRKRTLRRL substrate. (b) To determine background phosphorylation of substrates other than VRKRTLRRL, the assay was performed in the absence of VRKRTLRRL. In both instances, background phosphorylation was always $<0.05 \%$ of added cpm and not different in GMC that had been exposed to any of the test media, $\mathrm{H}-7$, or staurosporine. This confirms that the low level of background phosphorylation detected by this assay was constant, was not influenced nonspecifically by the test media, and thus did not influence the interpretation of the final result. Results are expressed as PKC dependent phosphorylation, $\mathrm{pmol} / \mathrm{min}$ per $\mathrm{mg}$ GMC protein.

\section{Statistical analysis}

Results are expressed as mean \pm SEM. Statistical analysis was made using an unpaired Student's $t$ test or ANOVA with a Bonferroni correction as appropriate. For each experiment, $n$ refers to the number of studies (each in triplicate).

\section{Materials}

[ $\left.{ }^{3} \mathrm{H}\right]$ Arachidonate and $\left[\tau-{ }^{32} \mathrm{P}\right]$ ATP were purchased from Amersham Corp., Arlington Heights, IL. Goat anti-rabbit IgG antibody was purchased from Pel-Freez Biologicals, Rogers, AR. The VRKRTLRRL substrate was a generous gift from Dr. Lynn E. Heasley and Prof. Gary L. Johnson, National Jewish Center for Immunology and Respiratory Medicine, Denver, $\mathrm{CO}$. The specific $\mathrm{PGE}_{2}$ and $\mathrm{TXB}_{2}$ antibodies were a generous gift from Dr. Frank Fitzpatrick, University of Colorado Health Sciences Center, Denver, CO. The specific 6-keto-PGF ${ }_{1 \alpha}$ antibody was a generous gift from Dr. Ken Allen, Colorado State University, Fort Collins, $\mathrm{CO}$. All other reagents used were of the highest grade available from Sigma Chemical Co., St. Louis, MO.

\section{Results}

Effects of test media on eicosanoid production by GMC. In the presence of control medium (D-glucose $5 \mathrm{mM}$ ), GMC pro-

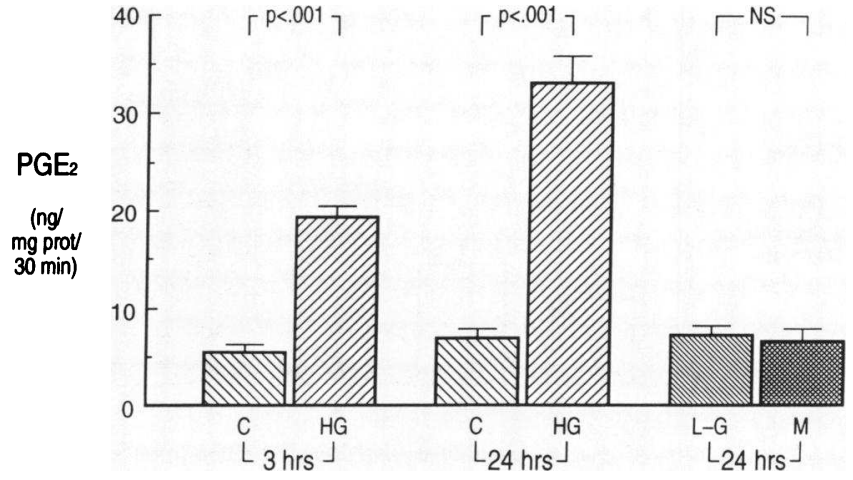

Figure 1. Basal production rates of $\mathrm{PGE}_{2} / 30 \mathrm{~min}$ per $\mathrm{mg}$ cell protein by GMC monolayers after 3- or 24-h exposure to control medium (C) [D-glucose $5 \mathrm{mM}$ ], or high glucose medium $(H G)$ [D-glucose 20 $\mathrm{mM}$ ], and 24-h exposure to either L-glucose osmotic control medium $(L-G)$ or mannitol osmotic control medium $(M)(n=3)$.

duced predominantly $\mathrm{PGE}_{2}$, with lesser quantities of 6-keto$\mathrm{PGF}_{1 \alpha}$ and very small quantities of $\mathrm{TXB}_{2}$. This eicosanoid production ratio is very similar to that reported by others for cultured rat GMC $(9,43)$. Exposing GMC to a high glucose medium (glucose $20 \mathrm{mM}$ ) for $3 \mathrm{~h}$ produced a marked and significant increase in the basal production rate of $\mathrm{PGE}_{2}$ per 30 min by GMC ( $359 \%$ vs control medium) (Fig. 1). Prolongation of high glucose exposure to $24 \mathrm{~h}$ further increased the basal production rates of $\mathrm{PGE}_{2}$ by GMC ( $480 \%$ vs control medium). Exposure to high glucose medium also increased GMC production of 6-keto-PGF ${ }_{1 \alpha}$ (the stable metabolite of $\mathrm{PGI}_{2}$ or prostacyclin) at $3 \mathrm{~h}$ (control: $376 \pm 19$ vs high glucose: $1,108 \pm 44 \mathrm{pg} /$ mg protein per $30 \mathrm{~min}, P<0.001$ ) and $24 \mathrm{~h}$ (control: $482 \pm 36$ vs high glucose: $1,575 \pm 60, P<0.001$ ). Relative to $\mathrm{PGE}_{2}$ and $\mathrm{PGI}_{2}$, GMC produce trivial quantities of thromboxane ( $\mathrm{TXA}_{2}$ ), nevertheless, GMC production of $\mathrm{TXB}_{2}$ (the stable metabolite of $\mathrm{TXA}_{2}$ ) was also increased in the presence of a high glucose medium at $3 \mathrm{~h}$ (control: $181 \pm 17$ vs high glucose: $374 \pm 28 \mathrm{TXB}_{2} \mathrm{pg} / 30 \mathrm{~min}$ per $\mathrm{mg}$ protein, $\left.P<0.01\right)$ and $24 \mathrm{~h}$ (control: $188 \pm 20$ vs $386 \pm 28, P<0.004$ ). These effects were specific for the high D-glucose medium and not related to changes in extracellular osmolality because they were not reproduced by 24-h exposure to either of the osmotic control media (Fig. 1). Furthermore, the fact that the medium containing the poorly metabolized glucose isomer (L-glucose) did not influence eicosanoid production suggests that the intracellular metabolism of D-glucose was essential for glucose-induced changes in GMC eicosanoid production to occur.

Glucose concentration dependency of changes in GMC eicosanoid production. Fig. 2 shows that glucose-induced increases in GMC-PGE 2 production were glucose concentration dependent up to a threshold glucose concentration of $20 \mathrm{mM}$. A similar profile of glucose concentration dependence was observed for GMC 6-keto-PGF ${ }_{1 \alpha}$ and $\mathrm{TXB}_{2}$ production (data not shown). The time dependency of glucose-induced increases in GMC eicosanoid production was similar for all three, requiring at least 2-h exposure to the high glucose medium before significant increases in basal eicosanoid production rates occurred.

Effect of exogenous arachidonic acid on $P G E_{2}$ production by $G M C$. The fact that high extracellular glucose concentrations increased the basal production rates of all eicosanoids by a similar order of magnitude implies that glucose acted to in- 


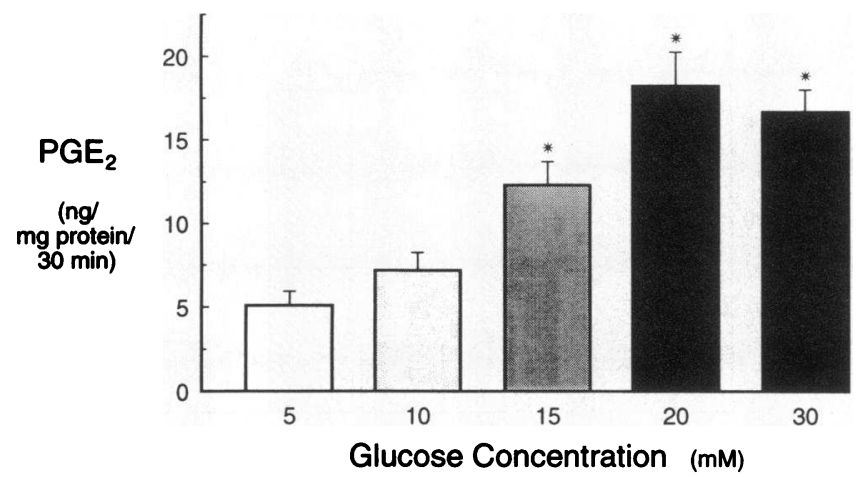

Figure 2. Glucose concentration dependency of $\mathrm{PGE}_{2}$ production by GMC measured after 24-h exposure to culture media containing various concentrations of D-glucose. ${ }^{*} P<0.01$ vs glucose $5 \mathrm{mM}, n=3$.

crease the availability of a common substrate for their synthesis, notably arachidonic acid. The next series of studies thus examined the effect of elevated extracellular glucose concentrations on endogenous arachidonic acid release by GMC. Table I shows that supplementing the control or high glucose media with exogenous arachidonic acid ( $30 \mu \mathrm{M})$ eliminated the high glucose-induced increase in $\mathrm{PGE}_{2}$, suggesting that glucose-induced increases in GMC eicosanoid production primarily resulted from enhanced availability of endogenous arachidonic acid.

Effects of test media on $\left[{ }^{3} \mathrm{H}\right]$ arachidonic acid release by $G M C$. To examine specifically whether high glucose concentrations directly enhanced the release of endogenous arachidonic acid from GMC, the release of $\left[{ }^{3} \mathrm{H}\right]$ arachidonate from preloaded GMC was examined. Fig. 3 shows that $3-h$ incubation with the high glucose medium induced a marked and significant increase in endogenous arachidonic acid release by GMC ( $177 \%$ vs control medium). This effect was sustained with prolonged exposure to the high glucose medium for $24 \mathrm{~h}$. In contrast, 24-h exposure to the osmotic control media did not reproduce the effect of the high glucose medium.

Effect of extracellular glucose concentration on reincorporation of arachidonic acid by GMC. To determine whether glucose stimulated the release of arachidonic acid from GMC, rather than inhibited arachidonic acid reincorporation, GMC were exposed to control or high glucose medium for $24 \mathrm{~h}$. Thereafter, the incorporation of $\left[{ }^{3} \mathrm{H}\right]$ arachidonic acid by

Table I. Effect of Exogenous Arachidonic Acid on $P G E_{2}$ Production by GMC

\begin{tabular}{|c|c|c|}
\hline \multirow[b]{2}{*}{ Experimental group } & \multicolumn{2}{|c|}{$\mathrm{PGE}_{2}$ Production } \\
\hline & -Arachidonic acid & +Arachidonic acid \\
\hline & \multicolumn{2}{|c|}{$n g / m g$ protein per $30 \mathrm{~min}$} \\
\hline Control & $6.4 \pm 0.6$ & $76.3 \pm 8.1^{*}$ \\
\hline High glucose & $32.1 \pm 3.1^{*}$ & $84.1 \pm 4.2^{*}$ \\
\hline
\end{tabular}

GMC monolayers were exposed to control or high glucose medium (glucose $20 \mathrm{mM}$ ) for $24 \mathrm{~h} \pm$ exogenous arachidonic acid $(30 \mu \mathrm{M})$ before the measurement of $\mathrm{PGE}_{2}$ production. ${ }^{*} P<0.001$ vs control medium. There was no significant difference in $\mathrm{PGE}_{2}$ production between control vs high glucose medium in the presence of arachidonic acid $(n=3)$.

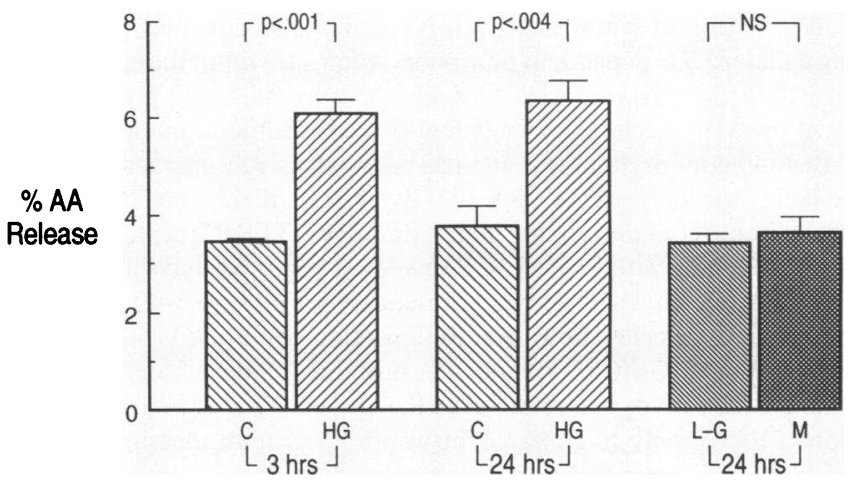

Figure 3. Effects of the various test media on percentage of arachidonic acid release per $30 \mathrm{~min}$ by GMC. The GMC monolayers prelabelled with $\left[{ }^{3} \mathrm{H}\right]$ arachidonic acid were exposed to control $(C)$ or high glucose medium $(H G)$ for 3 and $24 \mathrm{~h}$, or L-glucose osmotic control medium $(L-G)$ and mannitol osmotic control medium $(M)$ for $24 \mathrm{~h}$ (see Results) $(n=3)$.

GMC was measured over a 30-min period, a time period identical to that used for the measurement of arachidonic acid release. After exposure to the high glucose medium, the percentage of $\left[{ }^{3} \mathrm{H}\right]$ arachidonic acid incorporation by GMC was slightly increased (control medium: $16.2 \pm 0.2 \%$ vs high glucose medium: $17.7 \pm 0.4 \%, P<0.05, n=3$ ). These results confirm that the increased quantities of $\left[{ }^{3} \mathrm{H}\right.$ ] arachidonic acid measured in the supernatant of GMC monolayers exposed to high glucose concentrations represented glucose-stimulated release of endogenous arachidonic acid by GMC rather than reduced reincorporation.

Effect of test media on in situ PKC activity in GMC. High extracellular glucose concentrations have been shown to activate PKC in endothelial, vascular smooth muscle, and GMC in culture $(30,32,33)$. Furthermore, PKC activation directly via phorbol esters, or via hormonal stimulation, has been shown to augment arachidonic acid release and prostaglandin production by various cell types (17-26). Thus, the next series of studies examined whether PKC activation was involved in the mechanism(s) whereby glucose stimulated increased arachidonic acid release and increased eicosanoid production by GMC. Fig. 4 shows that after 3-h exposure to high D-glucose (20 mM) medium, in situ PKC activity was markedly increased compared to the PKC activity measured in GMC exposed to control medium (D-glucose $5 \mathrm{mM}$ ) and was sustained for up to $24 \mathrm{~h}$ with continued exposure to the high glucose medium. In contrast, 24-h exposure to the two osmotic control media produced no appreciable stimulation of in situ PKC activity, confirming that PKC activation was not osmotically mediated but did require the increased metabolism of D-glucose (Fig. 4). The glucose concentration dependency of PKC activation in GMC is shown in Fig. 5. Maximal glucose-induced PKC activation was observed at a glucose concentration of $20 \mathrm{mM}$.

To evaluate the role of PKC activity in mediating glucoseinduced increases in arachidonic acid release and eicosanoid production by GMC, two relatively specific but dissimilar inhibitors of PKC were used (H-7 and staurosporine) $(44,45)$. GMC were coincubated with either $\mathrm{H}-7$ (in $0.1 \%$ DMSO) or staurosporine in either control medium or high glucose medium for $24 \mathrm{~h}$ before determining PKC activity. DMSO alone 


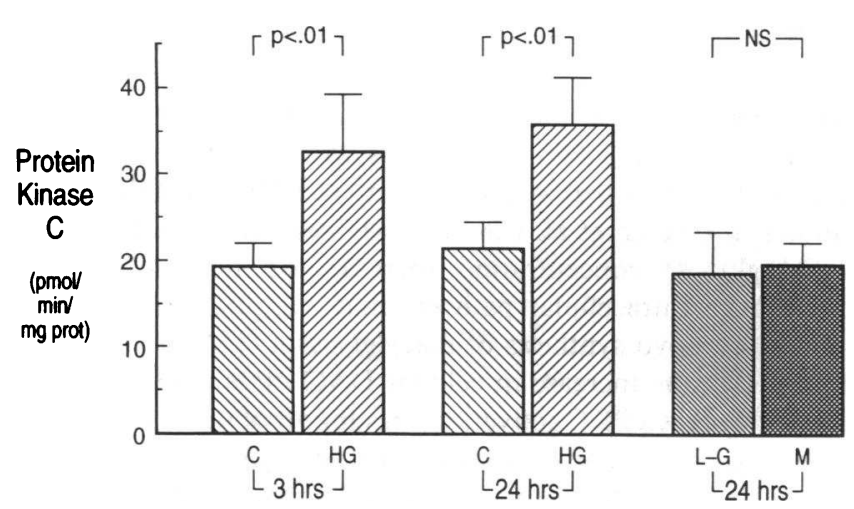

Figure 4. Glucose-induced PKC activity in GMC monolayers. Confluent GMC monolayers were exposed to control $(C)$ or high glucose $(H G)$ medium for 3 and $24 \mathrm{~h}$, or to L-glucose osmotic control medium ( $L-G)$ or mannitol osmotic control medium $(M)$ for $24 \mathrm{~h}$ before measuring PKC activity. PKC activity was measured in situ in digitonin-permeabilized GMC by determining the phosphorylation of a PKC-specific peptide substrate (VRKRTLRRL). Results are expressed as picomoles phosphate transferred to this substrate per minute per milligram GMC protein $(n=4)$.

had no effect on basal or glucose-stimulated PKC activity (data not shown). With control medium, $\mathrm{H}-7$ at a concentration of $50 \mu \mathrm{M}$ or staurosporine ( $1 \mu \mathrm{M})$ had little effect on basal PKC activity. However, when coincubated with the high glucose medium, both $\mathrm{H}-7$ and staurosporine significantly inhibited glucose-induced PKC activation in GMC (Fig. 6).

The role of $P K C$ in glucose-induced changes in arachidonic acid release and prostaglandin production by GMC. Fig. 7 shows that in the absence of PKC inhibitors, 3- or 24-h incubations with high glucose medium significantly augmented arachidonic acid release by GMC. However, when the high glucose medium was supplemented with either H-7 or staurosporine, glucose-induced increases in arachidonic acid release were prevented, suggesting that glucose-induced increases in arachidonic acid release by GMC are dependent on the capacity of glucose to activate PKC.

Increased arachidonic acid release is often taken to represent $\mathrm{PLA}_{2}$ activation. It was possible therefore that $\mathrm{H}-7-$ and staurosporine-induced inhibition of glucose-stimulated increases in arachidonic acid release represented nonspecific inhibition of $\mathrm{PLA}_{2}$ by these agents. To examine this possibility,

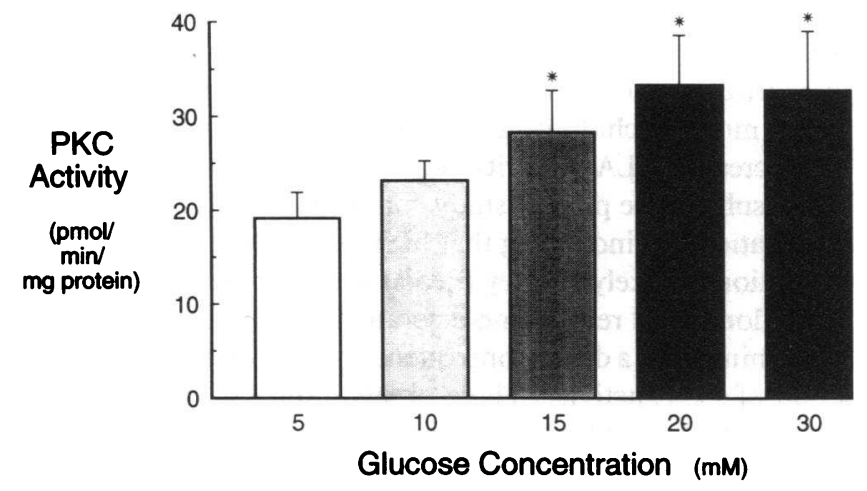

Figure 5. Glucose concentration dependency of PKC activation in GMC exposed to culture media containing various D-glucose concentrations for 24 h. ${ }^{*} P<0.01$ vs glucose $5 \mathrm{mM}, n=3$.

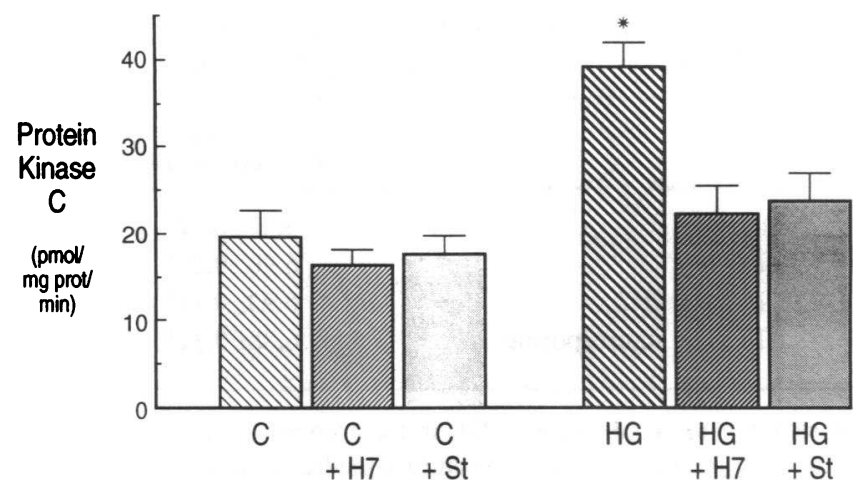

Figure 6. Inhibition of glucose-induced PKC activity by $\mathrm{H}-7$ and staurosporine. Confluent GMC monolayers were exposed to control (C) or high glucose medium $(H G) \pm \mathrm{H}-7(50 \mu \mathrm{M})$ or \pm staurosporine (St) $(1 \mu \mathrm{M})$ for $24 \mathrm{~h}$ before measuring PKC activity. ${ }^{*} P<0.01$ vs $\mathrm{C}$ and vs $\mathrm{C}+\mathrm{H}-7$ and vs $\mathrm{C}+\mathrm{St}(n=3)$.

GMC were preloaded with $\left[{ }^{3} \mathrm{H}\right]$ arachidonic acid for $24 \mathrm{~h}$ before a 30-min incubation with exogenous $\operatorname{PLA}_{2}(1 \mathrm{U} / \mathrm{ml}) \pm \mathrm{H}-7$ or staurosporine. Table II shows that exogenous PLA $\mathrm{P}_{2}$ significantly increased $\left[{ }^{3} \mathrm{H}\right.$ ] arachidonic acid release by GMC. The addition of $\mathrm{H}-7$ or staurosporine did not inhibit $\mathrm{PLA}_{2}$-induced arachidonic acid release, confirming that the PKC inhibitors used in the present study did not nonspecifically inhibit PLA activity.

The next study examined the effects of $\mathrm{H}-7$ and staurosporine on glucose-induced increases in $\mathrm{PGE}_{2}$ production by GMC. Fig. 8 shows that exposing GMC to high glucose medium in the presence of either PKC inhibitor markedly attenuates the high glucose-induced increase in $\mathrm{PGE}_{2}$ production. Together, these data demonstrate that high extracellular glucose concentrations directly increase eicosanoid production by GMC via glucose-induced increases in endogenous arachidonic acid release, which in turn depends on glucose-induced PKC activation in GMC.

\section{Discussion}

Mesangial cells are an abundant source of glomerular eicosanoids and the present study demonstrates that elevated extracel-

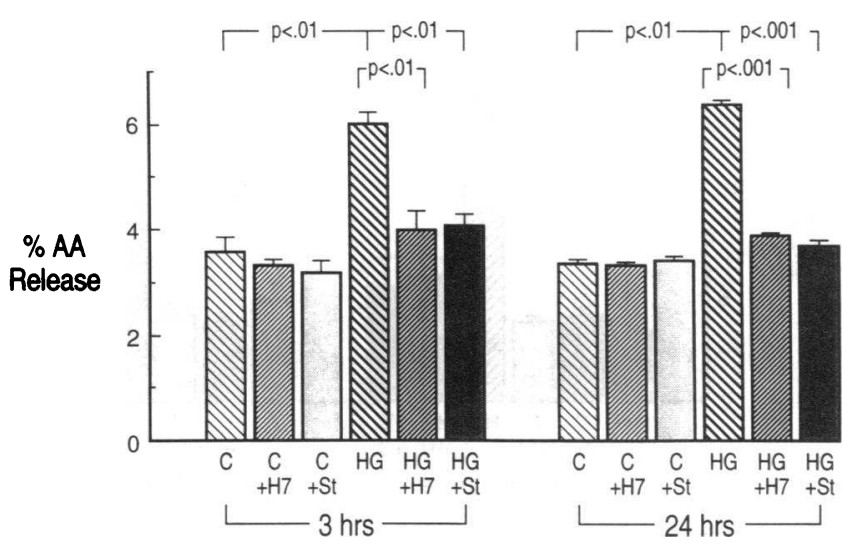

Figure 7. Effect of PKC inhibition on glucose-stimulated arachidonic acid release by GMC. Percentage of $\left[{ }^{3} \mathrm{H}\right]$ arachidonic acid release by preloaded GMC was measured after 3- and 24-h exposure to control $(C)$ or high glucose $(H G) \pm \mathrm{H}-7$ or \pm staurosporine $(\mathrm{St})(n=3)$. 
Table II. Effects of Exogenous PLA $A_{2}$ on Percentage of $\left[{ }^{3} \mathrm{H}\right]$ Arachidonic Acid Release by GMC per $30 \mathrm{~min}$

\begin{tabular}{lc}
\hline & $\begin{array}{c}\text { Percentage of [3 } \mathrm{H} \text { ]arachidonic } \\
\text { acid release by GMC }\end{array}$ \\
\hline Basal & $3.22 \pm 0.12$ \\
$+\mathrm{PLA}_{2}$ & $6.90 \pm 0.27^{*}$ \\
$+\mathrm{PLA}_{2}+\mathrm{H}-7$ & $6.93 \pm 0.15^{*}$ \\
$+\mathrm{PLA}_{2}+$ staurosporine & $6.88 \pm 0.31^{*}$ \\
\hline
\end{tabular}

Basal refers to unstimulated GMC in the presence of control medium. $\mathrm{PLA}_{2}(1 \mathrm{U} / \mathrm{ml})$ was added to the culture medium alone, or the presence of $\mathrm{H}-7(50 \mu \mathrm{M})$ or staurosporine $(1 \mu \mathrm{M})$ during the 30 -min period during which arachidonic acid release was measured. ${ }^{*} P<0.001$ vs Basal $(n=3)$.

lular glucose concentrations directly and independently increase the basal production rates of $\mathrm{PGE}_{2}, \mathrm{PGI}_{2}$, and $\mathrm{TXA}$ by cultured rat glomerular mesangial cells. This effect is apparent within hours of exposure to high glucose and persists for at least $24 \mathrm{~h}$ with continued exposure. These observations are consistent with a previous report demonstrating that chronic exposure to a high glucose medium ( $30 \mathrm{mM}$ ) for 10-14 d increased the production of predominantly $\mathrm{PGE}_{2}$ by cultured rat GMC (9). Until now however, the mechanism underlying this potentially important action of glucose has remained undefined. In pursuit of such a mechanism, the present study demonstrates that elevated extracellular glucose concentrations directly increase endogenous arachidonic acid release by GMC.

The regulation of endogenous arachidonic acid release by GMC is complex and rate limiting for eicosanoid production (16). Recent evidence suggests an important role for PKC in the regulation of arachidonic acid release (17-26). Specifically, PMA, which binds to and activates PKC, has been shown to simulate arachidonic acid release and eicosanoid production by many cell types including the mesangial cell (17-26). Additional studies support a role for PKC in the hormonal regulation of glomerular arachidonic acid release and $\mathrm{PGE}_{2}$ production (25-27). The present study demonstrates that elevated

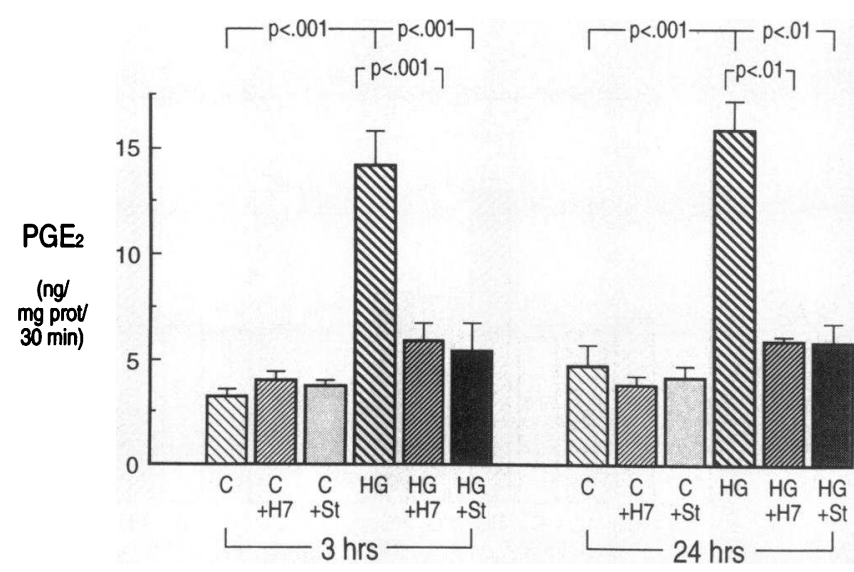

Figure 8. Effect of $\mathrm{PKC}$ inhibition on glucose-stimulated $\mathrm{PGE}_{2}$ release by GMC monolayers. GMC monolayers were exposed to control $(C)$ or high glucose $(H G)$ medium for 3 and $24 \mathrm{~h} \pm \mathrm{H}-7$ or \pm staurosporine (St) before determining basal $\mathrm{PGE}_{2}$ production $\mathrm{ng} / 30 \mathrm{~min}$ per $\mathrm{mg}$ GMC protein $(n=3)$. extracellular glucose concentrations induce a sustained activation of PKC in GMC. This result is consistent with a preliminary report showing that glucose-induced PKC activation is sustained for many days in cultured GMC (46). With regard to the mechanism whereby glucose activates PKC in GMC, the studies of Craven et al. (28) recently demonstrated that elevated glucose concentration increase the flux of glucose through an intracellular pathway that culminates in the enhanced de novo synthesis of diacylglycerol (DAG) and concluded that the increase in cellular DAG mass contributes to glucose-induced PKC activation. In support of this conclusion, Ayo et al. (32) recently confirmed that high glucose concentrations ( $30 \mathrm{mM}$ ) for up to 1 wk caused at least a threefold increase in DAG mass in GMC. The present study lends further support to this hypothesis by demonstrating that elevated concentrations of a nonmetabolized isomer, L-glucose, did not activate PKC, implying that a product of glucose metabolism, such as DAG, is required for glucose-induced activation of PKC in GMC.

The glucose concentration required for maximal PKC activation $(20 \mathrm{mM})$ in GMC is compatible with blood glucose concentrations attained in experimental models of diabetes mellitus and poorly controlled diabetic patients. Moreover, the striking similarity between the concentration dependency of glucose-induced changes in PKC activity and GMC eicosanoid production suggests that these two events could be causally related. Concordant with this hypothesis, the present study demonstrates that two chemically dissimilar inhibitors of glucose-induced PKC activation, $\mathrm{H}-7$ and staurosporine, prevented both the glucose-induced increase in arachidonic acid release and eicosanoid production by GMC, suggesting that glucose-induced changes in eicosanoid metabolism may be mediated via glucose-induced PKC activation. However, as neither $\mathrm{H}-7$ nor staurosporine are totally specific in their inhibition of PKC, the role of concomitant inhibition of other kinases by these inhibitors cannot be excluded.

In most cell types, PLA $_{2}$ is believed to be the primary effector enzyme for arachidonic acid release (16) and in this regard, $\left[{ }^{3} \mathrm{H}\right]$ arachidonic acid release rates are often considered to be representative of $\mathrm{PLA}_{2}$ activity. PKC has been shown to increase $\mathrm{PLA}_{2}$ activity in many cell types, either by phosphorylation of a $40-\mathrm{kD}$ regulatory protein indistinguishable from lipocortin, and/or direct phosphorylation and posttranslational modification of $\mathrm{PLA}_{2}$ (47-49). PKC-induced activation of $\mathrm{PLA}_{2}$ could thus explain the PKC-dependent effect of glucose to increase arachidonic acid release by GMC. In this regard, $\mathrm{PLA}_{2}$ activity was shown to be increased in glomeruli isolated from diabetic rats, when compared to glomerular PLA $\mathrm{A}_{2}$ activity in control rats (15). Moreover, the diabetic glomeruli also released more arachidonic acid and eicosanoids suggesting that the increased $\mathrm{PLA}_{2}$ activity was of physiologic significance. The results of the present study complement and extend these observations by indicating that high extracellular glucose concentrations is likely the key mediator of increased glomerular arachidonic acid release and eicosanoid synthesis in these diabetic animals, as a direct consequence of PKC-mediated modulation of PLA $\mathrm{A}_{2}$ activity. These observations do not, however, exclude the possibility that diabetes-induced increases in glomerular eicosanoid synthesis could also occur as a consequence of additional changes in cyclooxygenase activity (8).

Glucose-induced increases in GMC eicosanoid production could have considerable pathophysiologic significance. Early 
diabetes mellitus is characterized by the development of glomerular hyperfiltration and these hemodynamic changes have been strongly implicated in the pathogenesis of diabetic glomerulopathy (50-52). Several studies suggest that increased glomerular production of the vasodilator prostaglandins $\mathrm{PGE}_{2}$ and $\mathrm{PGI}_{2}$ contributes to the early development of glomerular hyperfiltration in diabetes mellitus $(12,14,53)$. Hyperglycemia may be a key mediator of prostaglandin-mediated hyperfiltration, as illustrated by the fact that perfusion of isolated rat kidneys with high glucose concentrations increases GFR via a prostaglandin-dependent mechanism (54). The results of the present in vitro study demonstrate a novel cellular mechanism whereby elevated glucose concentrations could directly increase glomerular prostaglandin production and thus could impact the regulation of GFR.

In addition to their effects on glomerular hemodynamics, $\mathrm{PGE}_{2}, \mathrm{PGI}_{2}$, and TXA 2 also modify GMC proliferation (55, 56). It is possible therefore, that glucose-induced changes in eicosanoid production by GMC could also have powerful autocrine and paracrine effects on glomerular cell growth and thus could contribute to diabetes-associated glomerular growth abnormalities (57-59).

In conclusion, the present results demonstrate that glucoseinduced PKC activation in GMC may provide an important link between the diabetic state and abnormalities in glomerular eicosanoid production. Specifically, we have shown that glucose directly increases arachidonic acid release and eicosanoid production GMC via a PKC-dependent mechanism. On this background, we propose that these effects occur via PKC-induced activation of $\mathrm{PLA}_{2}$. In so doing, glucose-induced PKC activation provides a novel mechanism that directly implicates hyperglycemia in the dysregulation of glomerular arachidonic acid release and eicosanoid production that may ultimately impact glomerular function and growth and contribute to the development of diabetic glomerulopathy.

\section{Acknowledgments}

The authors thank Dr. Jay Westcott, Pulmonary Division, University of Colorado Health Sciences Center, Denver, CO, for his helpful advice and assistance with the eicosanoid assays. The authors also thank Carolyn Burke for the illustrations.

This work was supported by a grant from the National Institutes of Health (DK-19928).

\section{References}

1. Halushka, P. V., R. C. Rogers, and J. A. Colwell. 1977. Increased synthesis of prostaglandin-E-like material by platelets from patients with diabetes mellitus. N. Engl. J. Med. 297:1306-1310.

2. Johnson, M., H. E. Harrison, A. T. Raftery, and J. B. Elder. 1979. Vascular prostacyclin may be reduced in diabetes in man. Lancet. i:325-326.

3. Gerrard, J. M., M. J. Stuart, G. H. R. Rao, M. W. Steffes, S. M. Mauer, D. M. Brown, and J. G. White. 1980. Alteration in the balance of prostaglandin and thromboxane synthesis in diabetic rats. J. Lab. Clin. Med. 95:950-958.

4. Axelrod, L., and L. Levine. 1982. Plasma prostaglandin levels in rats with diabetes mellitus and diabetic ketoacidosis. Diabetes. 31:994-1001.

5. Rogers, S. P., and R. G. Larkins. 1981. Production of 6-oxo-prostaglandin $F_{1 \alpha}$ by rat aorta: influence of diabetes, insulin treatment and caloric deprivation. Diabetes. 30:935-939.

6. Lubawy, W. C., and M. Valentovic. 1982. Streptozotocin-induced diabetes decreases formation of prostaglandin from archidonic acid in intact rat lungs. Biochem. Med. 28:290-297.

7. Rosen, P., and K. Schror. 1990. Increased prostacyclin release from perfused hearts of acutely diabetic rats. Diabetologia. 18:391-394.

8. Schambelan, M., S. Blake, M. Sraer, M. Bens, M.-P. Nivez, and F. Wahbe.
1985. Increased prostaglandin production by glomeruli isolated from rats with streptozotocin-induced diabetes mellitus. J. Clin. Invest. 75:404-412.

9. Kreisberg, J. E., and P. Y. Patel. 1983. The effects of insulin, glucose and diabetes on prostaglandin production by rat kidney glomeruli and cultured mesangial cells. Prostaglandins Leukotrienes Med. 11:431-442.

10. Brown, D. M., J. M. Gerrard, J. Peller, G. H. R. Rao, and J. B. White. 1980. Glomerular prostaglandin metabolism in diabetic rats. Diabetes. 29(Suppl.):55-59.

11. Chaudari, A., and M. A. Kirschenbaum. 1984. Effect of experimental diabetes mellitus on eicosanoid biosynthesis in isolated rat glomeruli. Kidney Int. 25:326-331.

12. Craven, P. A., F. R. Caines, and F. R. DeRubertis. 1987. Sequential alterations in glomerular prostaglandin and thromboxane synthesis in diabetic rats: relationship to the hyperfiltration of early diabetes. Metab. Clin. Exp. 36:95103.

13. Rogers, S. P., and R. G. Larkins. 1982. Production of 6-oxo-prostaglandin $F_{1 \alpha}$ and prostaglandin $E_{2}$ by isolated glomeruli from normal and diabetic rats. $B r$. Med. J. 284:1215-1217.

14. Esmatjes, E., M. R. Fernanadez, I. Halperin, J. Camps, J. Gaya, V. Arroyo, F. Rivera, and D. Figuerola. 1985. Renal haemodynamic abnormalities in patients with short term insulin dependent diabetes mellitus: role of renal prostaglandins. J. Clin. Endocrinol. \& Metab. 60:1231-1236.

15. Craven, P. A., M. C. Patterson, and F. R. DeRubertis. 1988. Role of enhanced arachidonate availability through phospholipase $A_{2}$ pathway in mediation of increased prostaglandin synthesis by glomeruli from diabetic rats. Diabetes. 37:429-435.

16. Flower, R. G., and G. J. Blackwell. 1976. The importance of phospholipase $A_{2}$ in prostaglandin synthesis. Biochem. Pharmacol. 25:285-291.

17. Bonventre, J. V., and M. Swidler. 1988. Calcium dependency of prostaglandin $\mathrm{E}_{2}$ production in rat glomerular mesangial cells. J. Clin. Invest. 82:168176.

18. Beaudry, G. A., L. W. Daniel, L. King, and M. Waite. 1983. 12-O-tetradecanoyl-phorbol-13-acetate stimulates rapid phospholipid deacylation. Biochim. Biophys. Acta. 750:274-281.

19. Ho, A. K., and D. C. Klein. 1987. Activation of $\alpha 1$-adrenoceptors, protein kinase $\mathrm{C}$ or treatment with intracellular free $\mathrm{Ca}^{2+}$ elevating agents increases pineal phospholipase $A_{2}$ activity: evidence that protein kinase $C$ may participate in the $\mathrm{Ca}^{2+}$ dependent $\alpha 1$-adrenergic stimulation of pineal phospholipase $\mathrm{A}_{2}$ activity. J. Biol. Chem. 262:11764-11770.

20. McIntyre, T. M., S. L. Reinhold, S. M. Prescott, and G. A. Zimmerman. 1987. Protein kinase $C$ activity appears to be required for the synthesis of platelet activating factor and leukotriene $\mathrm{B}_{4}$ by human neutrophils. J. Biol. Chem. 262:15370-15376.

21. Halenda, S. P., G. B. Zavoico, and M. B. Feinstein. 1985. Phorbol esters and oleoyl acetoyl glycerol enhance the release of arachidonic acid in platelets stimulated by $\mathrm{Ca}^{2+}$ ionophore A23187. J. Biol. Chem. 260:12484-12491.

22. Jeremy, J. Y., and P. Dandona. 1987. The role of diacylglycerol and protein kinase $\mathrm{C}$ in mediating adrenoceptor prostaglandin synthesis coupling in the rat aorta. Eur. J. Pharmacol. 136:311-316.

23. Parker, J., L. W. Daniel, and M. Waite. 1987. Evidence of protein kinase C involvement in phorbol diester-stimulated arachidonic acid release and prostaglandin synthesis. J. Biol. Chem. 262:5385-5393.

24. Godson, C., B. A. Weiss, and P. A. Insel. 1990. Differential activation of protein kinase $\mathrm{C} \alpha$ is associated with arachidonic acid release in Madin-Darby canine kidney cells. J. Biol. Chem. 265:8369-8372.

25. Weiss, B. A., and P. A. Insel. 1991. Intracellular $\mathrm{Ca}^{2+}$ and protein kinase C interact to regulate $\alpha 1$-adrenergic and bradykinin receptor stimulated phospholipase $A_{2}$ activation in MDCK cells. J. Biol. Chem. 266:2126-2133.

26. Craven, P. A., M. C. Patterson, and F. R. DeRubertis. 1988. Role for protein kinase $\mathrm{C}$ in the modulation of glomerular $\mathrm{PGE}_{2}$ production by angiotensin II. Biochem. Biophys. Res. Commun. 152:1481-1489.

27. Pfeilschifter, J., A. Kurtz, and C. Bauer. 1986. Role of phospholipase C and protein kinase $C$ in vasoconstrictor-induced prostaglandin synthesis in cultured rat mesangial cells. Biochem. J. 234:125-130.

28. Craven, P. A., C. M. Davidson, and F. R. DeRubertis. 1990. Increases in diacylglycerol mass in isolated glomeruli by glucose from de-novo synthesis of glycerolipids. Diabetes. 39:667-674.

29. Hise, M. K., and P. S. Mehta. 1980. Characterization and localization of calcium/phospholipid dependent protein kinase $\mathrm{C}$ during diabetic renal growth. Endocrinology. 123:1553-1558.

30. Lee, T.-S., L. C. MacGregor, S. J. Fluharty, and G. L. King. 1989. Differential regulation of protein kinase $\mathrm{C}$ and $\left(\mathrm{Na}^{+} / \mathrm{K}^{+}\right)$-ATPase activities by elevated glucose levels in retinal capillary endothelial cells. J. Clin. Invest. 83:90-94.

31. Craven, P. A., and F. R. DeRubertis. 1989. Protein Kinase C is activated in glomeruli from streptozotocin diabetic rats. Possible mediation by glucose. $J$. Clin. Invest. 83:1667-1675.

32. Ayo, S. H., R. Radnik, J. A. Garoni, D. A. Troyer, and J. I. Kriesberg. 1991. High glucose increases diacylglycerol mass and activates protein kinase $C$ in mesangial cell cultures. Am. J. Physiol. 261:F571-F577.

33. Williams, B., and R. W. Schrier. 1992. Characterization of glucose-in- 
duced in situ protein kinase $\mathrm{C}$ activity in cultured vascular smooth muscle cells. Diabetes. 41:1464-1472.

34. Takeda, K., H. Meyer-Lehnert, J. K. Kim, and R. W. Schrier. 1988. Effect of angiotensin II on $\mathrm{Ca}^{2+}$ kinetics and contraction in cultured rat glomerular mesangial cells. Am. J. Physiol. 254:F254-F266.

35. Meyer-Lehnert, H., and R. W. Schrier. 1988. Cyclosporin A enhances vasopressin-induced $\mathrm{Ca}^{2+}$ mobilization and contraction in mesangial cells. Kidney Int. 34:89-97.

36. Lowry, O. H., N. J. Rosebrough, A. L. Farr, and R. J. Randall. 1951. Protein measurement with the Folin phenol reagent. J. Biol. Chem. 193:265275.

37. Pradelles, P., J. Grassi, and J. Maclouf. 1985. Enzyme immunoassays of icosanoids using acetylcholinesterase as label: an alternative to radioimmunoassay. Anal. Chem. 57:1170-1173.

38. Rodbard, D., W. Bridson, and P. Rayford. 1969. Rapid calculation of radioimmunoassay results. J. Lab. Clin. Med. 74:770-781.

39. Heasley, L. E., and G. L. Johnson. 1989. Regulation of protein kinase C by nerve growth factor, epidermal growth factor and phorbol esters in $\mathrm{PC1}$ pheochromocytoma cells. J. Biol. Chem. 264:8646-8652.

40. Heasley, L. E., and G. L. Johnson. 1989. Detection of nerve growth factor and epidermal growth factor regulated protein kinases in PC12 cells with synthetic peptide substrates. Mol. Pharmacol. 35:331-338.

41. Davis, R. J., and M. P. Czech. 1985. Tumor promoting phorbol esters cause phosphorylation of epidermal growth factor receptors in fibroblasts at threonine-654. Proc. Natl. Acad. Sci. USA. 82:1974-1978.

42. Nishizuka, Y. 1986. Studies and perspectives of protein kinase C. Science (Wash. DC). 233:305-312.

43. Scharschmidt, L. A., and M. J. Dunn. 1983. Prostaglandin synthesis by rat glomerular mesangial cells in culture. Effects of angiotensin II and arginine vasopressin. J. Clin. Invest. 71:1756-1764.

44. Hidaka, H. F., M. Inagaki, S. Kawamoto, and Y. Sasaki. 1984. Isoquinoline sulfonamides, novel potent inhibitors of cyclic nucleotide dependent protein kinases and protein kinase C. Biochem. J. 23:5036-5041.

45. Matsumoto, H., and Y. Sasaki. 1989. Staurosporine, a protein kinase C inhibitor interferes with proliferation of arterial smooth muscle cells. Biochem. Biophys. Res. Commun. 158:105-109.

46. Studer, R. K., P. A. Craven, and F. R. DeRubertis. 1991. Role for protein kinase $\mathrm{C}$ in the mediation of increased fibronectin content of mesangial cells cultured in high glucose. J. Am. Soc. Nephrol. 2:299a. (Abstr.).

47. Touqui, L., B. Rothut, A. M. Shaw, A. Fradin, B. B. Vargaftig, and F. Russo-Marie. 1986. Platelet activation-a role for a $40 \mathrm{~K}$ anti-phospholipase $A_{2}$ protein indistinguishable from lipocortin. Nature (Lond.). 321:177-180.

48. Gronich, J. H., J. V. Bonventre, and R. A. Nemenoff. 1986. Identification and characterization of a hormonally-regulated form of $\mathrm{PLA}_{2}$ in rat renal mesangial cells. J. Biol. Chem. 263:16645-16651.

49. Nemenoff, R. A., S. Winitz, N. X. Qian, V. Van Putten, G. L. Johnson, and L. E. Heasley. 1993. Phosphorylation and activation of a high molecular weight form of phospholipase A2 by $\mathrm{p} 42$ microtubule-associated protein 2 kinase and protein kinase C. J. Biol. Chem. 268:1960-1964.

50. Hostetter, T. H., J. L. Troy, and B. M. Brenner. 1981. Glomerular hemodynamics in experimental diabetes mellitus. Kidney Int. 19:410-415.

51. Zatz, R., and B. M. Brenner. 1986. Pathogenesis of diabetic nephropathy: the hemodynamic view. Am. J. Med. 80:443-446.

52. Schrier, R. W., and H. Holzgreve. 1988. Hemodynamic factors in the pathogenesis of diabetic nephropathy. Klin. Wochenschr. 66:325-331.

53. Stahl, R. A. K., and F. Thaiss. 1987. Eicosanoids: biosynthesis and function in the glomerulus. Renal Physiol. 10:1-13.

54. Kasiske, B. L., M. P. O'Donnell, and W. F. Keane. 1985. Glucose-induced increases in renal hemodynamic function: possible modulation by renal prostaglandins. Diabetes. 34:360-364.

55. Menè, P., and M. J. Dunn. 1990. Prostaglandins and rat glomerular mesangial cell proliferation. Kidney Int. 37:1256-1262.

56. Menè, P., H. Abboud, and M. J. Dunn. 1990. Regulation of human mesangial cell growth in culture by thromboxane $\mathrm{A}_{2}$ and prostacyclin. Kidney Int. 38:232-239.

57. Rasch, R., and J. O. Rytter Norgaard. 1983. Renal enlargement: comparative autoradiographic studies of ${ }^{3} \mathrm{H}$-thymidine uptake in diabetic and uninephrectomized rats. Diabetologia. 25:280-287.

58. Mauer, S. M., M. W. Steffes, E. N. Ellis, D. E. R. Sutherland, D. M. Brown, and F. C. Goetz. 1984. Structural-functional relationships in diabetic nephropathy. J. Clin. Invest. 74:1143-1155.

59. Steffes, M. W., R. W. Bilous, D. E. R. Sutherland, and S. M. Mauer. 1992. Cell and matrix components of the glomerular mesangium in type I diabetes. Diabetes. 41:679-684. 